\title{
Cross-sectional Survey of Health Risk Behaviors of College Students in a Medical School in Xi'an \\ Yong-hong $\mathrm{MA}^{1}$, Jiao $\mathrm{TAN}^{1, *}$, Ming-juan $\mathrm{SHI}^{1}$, Jing $\mathrm{LEI}^{1}$ Ke MEN ${ }^{2}$ and Rong-qiang ZHANG $^{3}$
}

\author{
${ }^{1}$ Department of Epidemiology and Health Statistics, College of Public Health, \\ Xi'an Medical University, Xi'an, China \\ ${ }^{2}$ Institute for Research on Health Information and Technology of Xi'an Medical University, \\ Xi'an, Shaanxi, China; \\ ${ }^{3}$ Department of Epidemiology and Health Statistics, College of Public Health, \\ Shaanxi University of Chinese Medicine, Xianyang, China
}

${ }^{*}$ Corresponding author

Keywords: Students of Medical; Health-Risk Behaviors; Cross-Sectional Survey.

\begin{abstract}
By analyzing current status of health-risk behaviors and associated factors among college students, this study provides evidence for targeting to develop and implement behaviors intervention measures. In this paper, a stratified sampling method was used to investigate the health risk behaviors of 770 college students. Variance analysis, linear regression and other statistical methods were used to investigate the health risk behaviors and differences of college students. The results show that health risk behaviors among medical students affected by many factors, including the male students more prone to health-risk behaviors who have higher family income and poor academic performance. Female students than male in unreasonable weight lose and poor diet. As the grade increased suicide also increased. In conclusion, students' health risk behaviors occur more commonly, universities should take place against situation and features of health risk behaviors of college students, to carry out targeted health education and behavioral intervention.
\end{abstract}

\section{Introduction}

Health risk behavior refers to the behavior that the individual or group causes direct or indirect damage to health, intact state and lifelong quality of life, which deviates from the expectation of individuals, families, schools and society [1,2]. Affected by factors such as the deterioration of China's medical and health care system and the deterioration of the practicing medical environment, the pressure on medical students to learn is becoming more and more serious, which is bound to lead to the occurrence of college students' health risk behaviors [3,4]. This study investigates the status of the occurrence of health risk behaviors in medical college students, and provides a theoretical basis for formulating the prevention and control of the occurrence of adolescent health risk behaviors and improving the physical and mental health of college students.

\section{Objects and Methods}

\subsection{Object}

This study was conducted in April 2017, which focused on medical university students and used a stratified sampling method to randomly select a certain number of college students as the survey subjects. A total of 800 questionnaires were distributed and 770 questionnaires were valid, with an effective rate of $96.25 \%$.

\subsection{Methods}

This study was based on the Youth Risk Behavior Surveillance System (YRBSS) of the United States Center for Disease Control and Prevention, the "Health Questionnaire for College Students' Health Risk Behavior" and relevant literature [4-7], 10 dangerous behaviors that endanger college 
students' physical and mental health were selected: accidental injuries, violent injuries, smoking, drinking, unreasonable weight loss, unreasonable diet, suicide, sexual behavior, lack of physical exercise, and internet addiction. After pre-investigating, the Cronbach's alpha coefficient of the questionnaire was 0.705 , indicating that the reliability of the indicator was acceptable.

In this study, Excel 2015 and SPSS18.0 software were used to establish a database, and variance analysis, chi-square test, single factor and multi-factor regression analysis and other statistical methods were used for statistical research. The difference was statistically significant when $P<0.05$.

\section{Results}

\subsection{Gender differences in health risk behaviors of college students}

The gender differences of health risk behaviors in college students' were shown in Table 1 . Overall, there were significant differences in gender risk behavior among college students $(\mathrm{P}<0.05)$, except for suicide $(\mathrm{P}>0.05)$. In terms of accidental injury, violent injury, smoking, drinking, sexual behavior, lack of physical exercise and internet addiction, male performed significantly higher than female. In terms of unreasonable weight loss and unreasonable diet, female performed significantly higher than male.

Table 1. Comparison of gender differences in college students' health risk behaviors

\begin{tabular}{lllll}
\hline Gender & Male $(\mathrm{n}=317)$ & Female $(\mathrm{n}=447)$ & $\mathrm{t}$ & $\mathrm{P}$ \\
\hline Accidental Damage & $3.38 \pm 1.18$ & $3.09 \pm 1.02$ & 3.65 & 0 \\
Violent Injury & $3.88 \pm 1.26$ & $3.43 \pm 0.93$ & 5.66 & 0 \\
Smoking & $3.16 \pm 2.01$ & $2.1 \pm 0.55$ & 10.65 & 0 \\
Drink Alcohol & $5.05 \pm 1.68$ & $3.9 \pm 1.18$ & 11.1 & 0 \\
Unreasonable Weight Loss & $4.09 \pm 1.82$ & $4.48 \pm 1.74$ & -2.919 & 0.004 \\
Unreasonable Diet & $7.32 \pm 1.65$ & $8.02 \pm 1.56$ & -5.915 & 0 \\
Suicide & $3.77 \pm 1.26$ & $3.89 \pm 1.10$ & -1.401 & 0.161 \\
Sexual Behavior & $2.25 \pm 0.78$ & $2.13 \pm 0.63$ & 2.42 & 0.016 \\
Lack of Physical Exercise & $3.51 \pm 1.16$ & $2.99 \pm 1.12$ & 6.174 & 0 \\
Addicted to Internet & $3.86 \pm 1.71$ & $3.31 \pm 1.39$ & 4.915 & 0 \\
Total & $40.20 \pm 7.55$ & $37.36 \pm 5.07$ & 6.185 & 0 \\
\hline
\end{tabular}

\subsection{Differences of health risk behaviors between urban and rural districts of college} students

The difference between urban and rural students was shown in Table 2. Overall, there were significant urban-rural differences in college students $(\mathrm{P}<0.05)$. Specifically, there were differences in health risk behaviors such as violence injuries, drinking, unreasonable weight loss and lack of physical exercise $(\mathrm{P}<0.05)$. And these four kinds of health risk behaviors were higher for university students than for rural students.

Table 2. The difference health risk behavior between urban and rural district of college students

\begin{tabular}{lllll}
\hline Area & Rural $(\mathrm{n}=545)$ & Urban $(\mathrm{n}=223)$ & $\mathrm{t}$ & $\mathrm{P}$ \\
\hline Accident Hurt & $3.16 \pm 1.04$ & $3.31 \pm 1.21$ & -1.732 & 0.084 \\
Violence Hurt & $3.53 \pm 0.92$ & $3.83 \pm 1.42$ & -3.429 & 0.001 \\
Smoking & $2.55 \pm 1.45$ & $2.51 \pm 1.46$ & 0.372 & 0.71 \\
Drink Alcohol & $4.29 \pm 1.41$ & $4.60 \pm 1.73$ & -2.554 & 0.011 \\
Unreasonable Lose Weight & $4.22 \pm 1.76$ & $4.57 \pm 1.83$ & -2.421 & 0.016 \\
Unreasonable Diet & $7.68 \pm 1.63$ & $7.83 \pm 1.68$ & -1.145 & 0.252 \\
Suicide & $3.79 \pm 1.09$ & $3.97 \pm 1.34$ & -1.923 & 0.055 \\
Sexual Behavior & $2.17 \pm 0.70$ & $2.21 \pm 0.69$ & -0.758 & 0.449 \\
Lack of Body Training Exercise & $3.12 \pm 1.15$ & $3.39 \pm 1.18$ & -2.96 & 0.003 \\
The Internet Addiction & $3.48 \pm 1.57$ & $3.67 \pm 1.50$ & -1.548 & 0.122 \\
Total & $37.95 \pm 6.13$ & $39.86 \pm 6.76$ & -3.795 & 0 \\
\hline
\end{tabular}




\subsection{Other differences in college students' health risk behaviors}

The family income analysis indicated that there was significant difference in the different family income of college students' health risk behaviors $(\mathrm{F}=5.410, \mathrm{P}<0.05)$, except for unreasonable diet, lack of physical exercise and internet addiction $(\mathrm{P}>0.05)$. With the increase of family income, accidental injury, violence, smoking, drinking, unreasonable weight loss, suicide, sexual behavior and other risk behaviors increased.

The variance analysis showed that there were significant differences between different grades of college students $(\mathrm{P}<0.05)$. Further comparisons indicated that the lower grades showed a higher rate in unreasonable weight loss, unreasonable diet, and lack of physical exercise risk factors compared with the higher grades. Suicide risk factors were higher in the higher grades than the lower grades.

The mother's education level influenced college students' health risk behaviors. Overall, the mother's education level had different effects on the occurrence of college students' health risk behaviors $(\mathrm{F}=10.525, \mathrm{P}<0.05)$. According to the detailed analysis, the risk factors such as smoking, drinking, unreasonable weight loss, unreasonable diet and internet addiction were all related to the level of maternal education $(\mathrm{P}<0.05)$. The result showed that students with poor academic performance had higher health risk behaviors.

\subsection{Multivariate analysis of demographic variables on health risk behaviors of college students}

The simple linear regression analysis was performed on the subject's gender, age, family location (rural/urban), the only child, grade, family income, father's education level, mother's education level, and academic achievement. The total score of the health risk behavior of the subject was the dependent variable of the linear regression, and the demographic variable was the independent variable. The regression coefficient t-test for gender, grade, family location (rural/urban), the only child, family income, mother's education level, academic performance had significant difference on health risk behavior. And these variables were selected to product multivariate analysis.

As shown in Table 3, college students' health risk behaviors were related to students' gender, family income, and academic performance. Among these dangerous behaviors, male students with poor academic performance were more vulnerable to accidental injuries. Male college students with lower family income were more vulnerable to violence, smoking and other health risk behaviors. Male college students with higher family income and poor academic performance were more likely to suffer from the health risk behavior of drinking. Unreasonable weight loss and irrational diet occurred in female college students. Students in higher grades were more vulnerable to suicide risk behaviors. The occurrence of sexual behavior was related to multiple factors.

Table 3. Multivariate stepwise regression analysis of various health risk behaviors with demographic variables

\begin{tabular}{ll}
\hline Dependent variable & Standardized regression equation \\
\hline Total risk behavior & $\mathrm{Y}^{\wedge}=38.737-2.300 \mathrm{X}_{\text {Gender }}+1.094 \mathrm{X}_{\text {Family Income }}+0.779 \mathrm{X}_{\text {Academic score }}$ \\
accidental damage & $\mathrm{Y}^{\wedge}=3.338-0.261 \mathrm{X}_{\text {Gender }}+0.142 \mathrm{X}_{\text {Academic score }}$ \\
Violent injury & $\mathrm{Y}^{\wedge}=3.752-0.355 \mathrm{X}_{\text {Gender }}+0.252 \mathrm{X}_{\text {Family Income }}$ \\
Smoking & $\mathrm{Y}^{\wedge}=3.949-1.016 \mathrm{X}_{\text {Gender }}+0.121 \mathrm{X}_{\text {Family Income }}$ \\
Drink alcohol & $\mathrm{Y}^{\wedge}=5.183-1.012 \mathrm{X}_{\text {Gender }}+0.191 \mathrm{X}_{\text {Family Income }}+0.238 \mathrm{X}_{\text {Academic score }}$ \\
Unreasonable weight loss & $\mathrm{Y}^{\wedge}=4.683+0.540 \mathrm{X}_{\text {Gender }}-0.366 \mathrm{X}_{\text {Only Child }}-0.299 \mathrm{X}_{\text {Grade }}$ \\
Unreasonable diet & $\mathrm{Y}^{\wedge}=6.482+0.852 \mathrm{X}_{\text {Gender }}-0.273 \mathrm{X}_{\text {Grade }}+0.216 \mathrm{X}_{\text {Academic score }}$ \\
suicide & $\mathrm{Y}^{\wedge}=3.493+0.179 \mathrm{X}_{\text {Grade }}$ \\
Sexual behavior & $\mathrm{Y}^{\wedge}=1.286-0.111 \mathrm{X}_{\text {Gender }}+0.045 \mathrm{X}_{\text {Age }}+0.073 \mathrm{X}_{\text {Family Income }}-0.105 \mathrm{X}_{\text {Father's Education }}$ \\
Lack of physical exercise & $+\mathrm{Y}^{\wedge}=4.122 \mathrm{X}_{\text {Mother's Education }}$ \\
addicted to Internet & $\mathrm{Y}^{\wedge}=3.156-0.483 \mathrm{X}_{\text {Gender }}+0.2 \mathrm{X}_{\text {Home Location }}-0.237 \mathrm{X}_{\text {Grade }}$ \\
\hline
\end{tabular}




\section{Discussion}

\subsection{Overall analysis of college students' health risk behavior}

From this survey, we can see that the only child does not affect the occurrence of college students' health risk behavior. Among them, gender, family income, and academic achievement are the main factors affecting the occurrence of college students' health risk behaviors, which are mainly manifested in male college students with higher family income and poor academic performance, and are more prone to health risk behaviors [8].

\subsection{Specific analysis of college students' health risk behaviors}

In terms of gender differences, there is no significant difference with suicide, and it also has no differences in other risk factors, which is agree with the conclusions of other researches on health risk behaviors of college students. Unreasonable diet and unreasonable weight loss were significantly higher in female than in male. However, the other health risk behaviors were higher in men than in women, which are related to the fact that female college students pay more attention to their appearance. Therefore, school educators should strengthen scientific weight-loss instruction and nutrition instruction for female undergraduates and establish a correct aesthetic concept [11].

In the study of the influence of college students on their health risk behaviors, unreasonable weight loss, unreasonable diet, and lack of physical exercise risk factors in lower grades are higher than in high grades, which are related to the lack of awareness of physical exercise among current college students [12]. The risk factors for suicide are higher in the higher grades than in the lower grades. This is because the higher grade students are faced with pressures such as employment.

In the family income analysis of college students', the health risk behaviors such as accidental injury, violent injury, smoking, drinking, unreasonable weight loss, suicide, and sexual behavior increased with the increase of family income. This maybe related to college students with higher family income who are exposed to more social bad temptations and more autonomous behaviors [13].

\section{Conclusion}

In summery, in the intervention of college students' health risk behaviors, the degree of concern for college students with higher family income should be increased. Second, because students living in cities receive more information channels, rich cultural life, more convenient facilities, and more opportunities for development, they also face more temptations, resulting in their risk of violence, drinking, and other harmful health behaviors [14]. In addition, attention should be paid to the prevention of health risk behaviors among college students with poor academic achievement, because of their significant differences in risk factors such as accidental injury, drinking, and internet addiction [15]. In addition, the level of parental education is also a major factor affecting the occurrence of college students' health risk behaviors, especially in terms of sexual behavior and Internet addiction. Therefore, at the same time of the intervention of the college students' health risk behaviors, it is urgent to strengthen family education. On the basis of investigating the risk behaviors of high-risk college students, we should focus on influencing factors for multiple, well-produced health risks and conduct research on different influencing factors to effectively reduce the risk behaviors of college students. Occur and promote the healthy growth of college students [16].

\section{Conflicts of Interest}

The authors declare no competing financial interests.

\section{Acknowledgments}

This work was funded by the Social Development Scientific and Technological Project, Shaanxi Science and Technology Department, Shaanxi Province (2016SF-245) and Special Research Project, 
Department of Education, Shaanxi Province (15JK1628).

\section{References}

[1] Ng B. Y., Kankanhalli A., Xu Y. C. Studying users' computer security behavior: A health belief perspective [J]. Decision Support Systems, 2009, 46 (4): 815-825.

[2] Wechsler H., Lee J. E., Kuo M., et al. Trends in college binge drinking during a period of increased prevention efforts: Findings from 4 Harvard School of Public Health College Alcohol Study surveys: 1993-2001 [J]. Journal of American College Health, 2002, 50 (5): 203-217.

[3] Huang T. T. K., Harris K. J., Lee R. E., et al. Assessing overweight, obesity, diet, and physical activity in college students [J]. Journal of American College Health, 2003, 52 (2): 83-86.

[4] Kisch J., Leino E. V., Silverman M. M. Aspects of suicidal behavior, depression, and treatment in college students: Results from the Spring 2000 National College Health Assessment Survey [J]. Suicide and Life-Threatening Behavior, 2005, 35 (1): 3-13.

[5] O’Brien M. C., McCoy T. P., Rhodes S. D., et al. Caffeinated cocktails: energy drink consumption, high-risk drinking, and alcohol-related consequences among college students [J]. Academic Emergency Medicine, 2008, 15 (5): 453-460.

[6] Brener N. D., McMahon P. M., Warren C. W., et al. Forced sexual intercourse and associated health-risk behaviors among female college students in the United States [J]. Journal of Consulting and Clinical Psychology, 1999, 67 (2): 252.

[7] Niemz K., Griffiths M., Banyard P. Prevalence of pathological Internet use among university students and correlations with self-esteem, the General Health Questionnaire (GHQ), and disinhibition [J]. Cyberpsychology \& Behavior, 2005, 8 (6): 562-570.

[8] Racette S. B., Deusinger S. S., Strube M. J., et al. Weight changes, exercise, and dietary patterns during freshman and sophomore years of college [J]. Journal of American College Health, 2005, 53 (6): 245-251.

[9] Buckworth J., Nigg C. Physical activity, exercise, and sedentary behavior in college students [J]. Journal of American College Health, 2004, 53 (1): 28-34.

[10]Schwartz S. J., Forthun L. F., Ravert R. D., et al. Identity consolidation and health risk behaviors in college students [J]. American Journal of Health Behavior, 2010, 34 (2): 214-224.

[11]Laska M. N., Pasch K. E., Lust K., et al. Latent class analysis of lifestyle characteristics and health risk behaviors among college youth [J]. Prevention Science, 2009, 10 (4): 376-386.

[12]Keating X. D., Guan J., Piñero J. C., et al. A meta-analysis of college students' physical activity behaviors [J]. Journal of American College Health, 2005, 54 (2): 116-126.

[13]DuRant R., Champion H., Wolfson M., et al. Date fighting experiences among college students: are they associated with other health-risk behaviors? [J]. Journal of American College Health, 2007, 55 (5): 291-296.

[14]Silverman J. G., Raj A., Mucci L. A., et al. Dating violence against adolescent girls and associated substance use, unhealthy weight control, sexual risk behavior, pregnancy, and suicidality [J]. Journal of the American Medical Association, 2001, 286 (5): 572-579.

[15]Greene G. W., Schembre S. M., White A. A., et al. Identifying clusters of college students at elevated health risk based on eating and exercise behaviors and psychosocial determinants of body weight [J]. Journal of the American Dietetic Association, 2011, 111 (3): 394-400.

[16]Greenberg M. T., Weissberg R. P., O'brien M. U., et al. Enhancing school-based prevention and youth development through coordinated social, emotional, and academic learning [J]. American Psychologist, 2003, 58 (6-7): 466. 